\title{
Acoustic comfort in large railway stations
}

\author{
Yue $\mathrm{Wu}^{\mathrm{a}}$, Jian Kang ${ }^{\mathrm{a}, \mathrm{b}^{*}}$, Wenzhong Zheng ${ }^{\mathrm{c}}$, Yongxiang $\mathrm{Wu}^{\mathrm{c}}$ \\ ${ }^{a}$ Key Laboratory of Cold Region Urban and Rural Human Settlement Environment Science and \\ Technology, Ministry of Industry and Information Technology, School of Architecture, Harbin institute of \\ Technology, Harbin, China \\ ${ }^{b}$ UCL Institute for Environmental Design and Engineering, University College London (UCL), London, \\ United Kingdom \\ ${ }^{c}$ School of Civil Engineering, Harbin Institute of Technology, Harbin, China \\ "Corresponding Author: J.kang@ucl.ac.uk, UCL Institute for Environmental Design and Engineering, \\ The Bartlett, University College London (UCL), London WC1HONN, United Kingdom. Tel: \pm 44(0)20 3108 \\ 7338
}

\begin{abstract}
Large railway stations attract a wide range of passengers and citizens, and these buildings are likely to have a complex acoustic environment. Previous studies have focused on reducing people's exposure to excessive sound levels caused by transportation, but more research is needed to assess people's preferences and ensure their psychophysical wellbeing. The aim of this study was to explore the complex aspects of the sound environment in large railway stations that contribute to acoustic comfort. On-site measurements and an acoustic comfort survey were performed at a case study site in Harbin, China. The results showed a significant positive correlation between the subjective comfort evaluations and objective measurements of the sound pressure level and reverberation time. Differences in dominant sound sources in different spaces lead to different evaluations of acoustic comfort. People prefer broadcast sound, but its intelligibility needs to be improved. When the density of people increases, the preference for speech sounds and activity sounds decline rapidly. With regard to demographic and social factors, older people and people with higher incomes and education levels are more tolerant of the environment.
\end{abstract}

Keywords: Auditory guide; Sound field; Sound environment; Security evacuation.

2020 Applied Acoustics

Date Received: 17 July 2019 Date Accepted: 7 November 2019

Available online: 22 November 2019. 


\section{Introduction}

Railway stations have traditionally been associated with waiting and transit spaces. In the past, this association was because the stations hosted a relatively limited number of functions [1]. Currently, however, large railway stations worldwide are being built to accommodate increasingly complicated functions and crowds, which has introduced more stringent requirements for the sound environment. Acoustic comfort, which is the most important index for evaluating soundscape [2], has also been widely studied in public spaces, including offices [3], large dining rooms [4], public libraries [5], commercial spaces [6] quiet and restorative areas [7,8]. In these studies, transportation noise sources are generally mentioned as the primary or secondary noise sources. Researchers have found that different types of vehicles have a specific impacts on the surrounding environment, for instance, noise from road traffic [9], trains [10], aircraft [11] and vessels [12]. These noises have been demonstrated to make diffuse people and disturb them in [13] residential areas [14], commercial areas [15], school areas [16], quiet natural areas [17] and port areas [18]. Several adverse effects have been associated with exposure to traffic noise [19]. Beyond its effects on the auditory system, noise causes annoyance [20], disturbs sleep [21] and impairs cognitive performance [22]. Furthermore, epidemiologic studies have demonstrated that environmental noise is associated with increased arterial hypertension, myocardial infarction, and stroke [23]. Moreover, aircraft and road traffic noise exposure have been associated with psychological symptoms [24]. In children, chronic aircraft noise exposure impairs reading comprehension and long-term memory and may be associated with increased blood pressure [25]. Generally, it has been found that continuous exposure to traffic noise causes people to suffer from various types of discomfort and appreciably reduces measures of well-being. However, little attention has been paid to people's levels of acoustic comfort inside transit spaces. People's comfort and psychophysical well-being are important in transit spaces and should be significant considerations during the designs of such spaces; however, further details concerning the phenomena and theory are still required.

In China's railway stations, the entrance hall, ticket office, integrated waiting hall and auxiliary space are all concentrated within a single large space [26]. As the number of functions increases, the types of sound sources also increase. The resulting complex acoustic environment leads to various adverse effects on user comfort and causes a series of acoustic problems, such as high environmental noise and poor language articulation [27]. Conversations between people are a primary behavioral factor influencing the sound environment and acoustic perceptions in railway stations. Studies have found that noise emissions from activities involving crowds of people can also affect the sound environments of public spaces [28]. Nie and Kang [29] proposed a crowd acoustic model and found a relationship between the crowd, sound pressure level, total population and number of people conversing. Wu and Kang [30] using the results of interviews and questionnaires, showed that conversational speech intelligibility is poor and that crowd noise is considered a main factor that affects broadcast clarity. Traffic sounds are another main sound source in railway stations. Bandyopadhyay et al. [31] measured the sound pressure level (SPL) on platforms and found that the SPL affects users' health. Broadcasts are an important aspect of the sound in railway stations. Liu et al. [32] used acoustic measurements and simulations to study the reverberation time $(\mathrm{RT})$ and the speech transmission index of public broadcasting systems. 
77 Excessive noise exposure caused by the enormous ventilation systems in large spaces also has

serious impacts. Tao et al. [33] evaluated the noise annoyance levels in a metro depot and the noise influence of its ventilation system on adjacent residential buildings. However, simply reducing the overall 'sound level' does not always result in the desired quality of life improvements. Many sound sources have been studied to evaluate their influences on the sound environment and acoustic comfort, but due to their increasing functions, the acoustic comfort levels in large railway stations have not been studied systematically.

Therefore, the goal of this paper is to study the effects of various sound sources on the sound environment and acoustic comfort in extra-large spaces using a soundscape approach. A typical large railway station in China was chosen as a case study. The overall comfort level and sound environment in the station's different functional zones were studied using both objective measurements and a questionnaire survey. First, the sonic composition and appropriateness were analyzed. Then, the effects of different types of sound sources in different zones on loudness, intelligibility, sound level, preference degree and acoustic comfort were analyzed.

\section{Methodology}

\subsection{Survey site}

The size of the station determines whether it has sufficient capacity to carry customer flow. The indexes for measuring its size include the number of platforms, number of trains per day, and the number of dispatched passengers yearly [34]. Table 1 shows the sizes of the busiest top 20 railway stations in China. For this study, a large railway station with a length of $310 \mathrm{~m}$, a width of $190 \mathrm{~m}$, and a volume of $1.2 \times 10^{6} \mathrm{~m}^{3}$ was chosen as the case study site. The selected station is representative: it is neither the largest nor the smallest among China's large railway stations, it has 18 platforms, and the number of passengers dispatched yearly is 110 million.

Table 1 The scale of railway stations in China (The busiest top 20) [34]

\begin{tabular}{lccc}
\hline Name & $\begin{array}{c}\text { Number of } \\
\text { platforms }\end{array}$ & $\begin{array}{c}\text { Number of } \\
\text { trains/day }\end{array}$ & $\begin{array}{c}\text { Number of passengers } \\
\text { dispatched yearly } \\
\text { (millions) }\end{array}$ \\
\hline Shanghai Hongqiao Railway Station & 30 & 520 & 678 \\
Guangzhou South Railway Station & 28 & 653 & 470 \\
Xian North Railway Station & 34 & 186 & 111 \\
Zhengzhou East Railway Station & 30 & 352 & 135 \\
Kunming South Railway Station & 30 & 118 & 54.6 \\
Nanjing South Railway Station & 28 & 508 & 236 \\
Hangzhou East Railway Station & 28 & 243 & 51.8 \\
Chengdu East Railway Station & 26 & 593 & 293 \\
Beijing South Railway Station & 24 & 406 & 320 \\
Changsha South Railway Station & 24 & 399 & 168 \\
Nanning East Railway Station & 24 & 204 & 115 \\
Shenzhen North Railway Station & 20 & 258 & 98.2 \\
Tianjin West Railway Station & 18 & 236 & 217 \\
Lanzhou West Railway Station & 18 & 186 & 60.8 \\
Shenyang South Railway Station & 18 & 296 & 237 \\
Harbin West Railway Station & 18 & 225 & 110 \\
Jinan East Railway Station & 18 & 259 & 146 \\
Dalian North Railway Station & 18 & 214 & 43.8 \\
Taiyuan South Railway Station & 18 & 209 & 48.6
\end{tabular}


101 Case studies of passenger activities are common in China and most Asian countries and even in some European countries [35-37]. The mixed functions inside the selected case site are representative, commonly found in urban transit spaces [38,39], and include cafés, bars, restaurants, shops, security checks, ticket checks, information boards, pharmacies, and bathrooms. Almost all these functions are concentrated in one large space, and because the station is the main city transportation hub, the daily flow of people is very large, which indicates that the building is likely to have a complex acoustic environment [40].

To facilitate a high pedestrian movement rate throughout the station, a total of 18 escalators and 10 elevators provide full stairs-free access to all areas. In total, there are 570 seats within the station, and 20,000 people use the station every day.

\subsection{SPL and RT measurements}

Previous studies have suggested that different sound sources and behavioral patterns influence the sound environment and the acoustic perceptions of users in open and indoor spaces and that the sound environment can, in turn, influence peoples' acoustic perceptions. The most important indexes that affect the sound environment are SPL and RT [13], which were measured by the following methods. The measurement points are shown in Fig. 2. The selected test points covered six different functional spaces, including the seating area, security check, ticket lobby, ticket check, restaurants, and shops. The ticket lobby is located on both sides of the entrance and connected by a hallway to form a coupled space. The ticket window is on one side of the lobby; the rest of the lobby is typically full of people waiting to buy tickets. The other five spaces are all located in the waiting hall; the security checkpoint faces the entrance; there are four baggage screening machines; people queue through security to enter the waiting hall; the seating area is behind the security checkpoint; seats are divided into north and south banks, and each bank consists of 56 rows; the shops are located near the seating areas in the waiting hall; the outside is enclosed by a $2 \mathrm{~m}$ high glass wall into a semiopen space; the ticket check is outside the seating area at the edge of the waiting hall; there is a large population density at check-in time; and the restaurants are small rooms on either side of the waiting hall.

Measurements were made during dense traffic periods. For each measurement point, an SPL meter was set to slow mode and A-weighting, and an instantaneous reading was taken every 10 s. To avoid sound source variability, each sound pressure level at each measurement point was tested 10 times; each measuring point was tested every hour, and the average value of the 10 sets of data was taken as the result of this measurement point. The measuring period lasted from 8:00 to 18:00. The equipment selection and measurement process followed the ISO3382 standard. The sound level meter microphone was positioned $1 \mathrm{~m}$ away from walls and other main reflectors and 1.2-1.5 $\mathrm{m}$ off the ground [41]. A total of $5 \mathrm{~min}$ of data were obtained at each measurement position, and the corresponding A-weighted equivalent SPL (LAeq) was derived. To avoid measurement error, each measurement in each space was taken from at least five random points at least $3 \mathrm{~m}$ apart. To avoid the impact of speech on the measurements, no people were talking within $3 \mathrm{~m}$ of the sound level meter [42]. The A-weighted SPLs measured at each point were averaged.

To understand the characteristics of the sound field in the waiting hall, the reverberation time in 6 areas of the waiting hall was measured at night when the trains had stopped. Only survey crews were present in the waiting hall during these measurements. An OS002 12-sided nondirectional sound source was adopted to play white noise [26]. As shown in Fig. 1, S represents a sound source position, and one sound source point was set in each area. $R$ denotes the position of a receiving point. An 801 sound level meter was used to test the reverberation time. Due to the large volume of the waiting hall, the difference in sound pressure level between most measuring point 
148 noise and background noise was less than the test range of T30. Therefore, the reverberation time

149 of each area was compared with the T20 value.

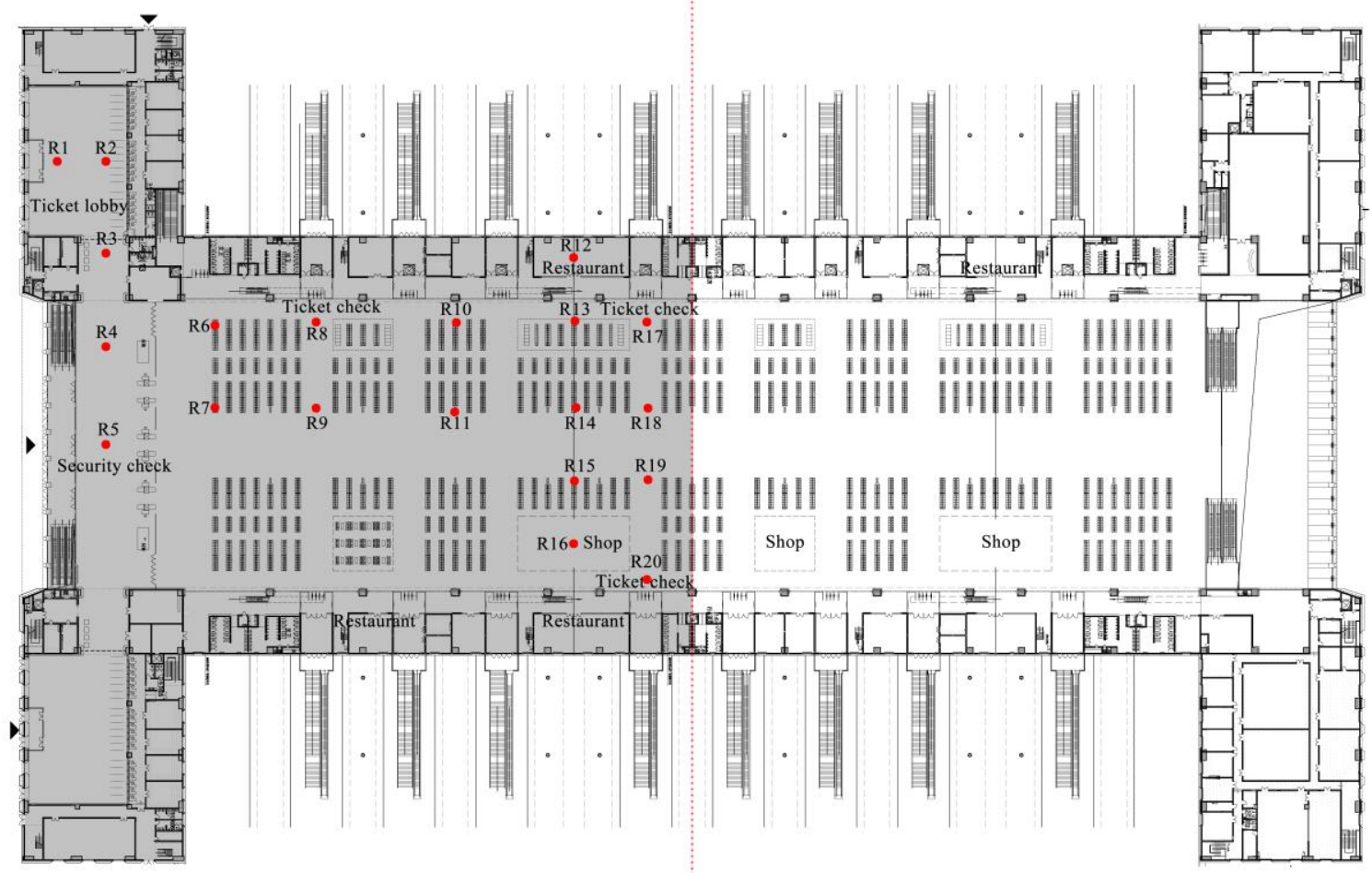

Fig. 1. The survey site and measurement points.

Table 2 Basic information on six typical spaces.

\begin{tabular}{|c|c|c|c|c|c|c|c|}
\hline & & Seating area & $\begin{array}{l}\text { Security } \\
\text { check }\end{array}$ & Ticket check & Ticket lobby & $\begin{array}{c}\text { Restaura } \\
\text { nt }\end{array}$ & Shop \\
\hline Space type & & Large space & Large space & Large space & Atrium space & $\begin{array}{l}\text { Small } \\
\text { space }\end{array}$ & $\begin{array}{c}\text { Small space } \\
\text { without a } \\
\text { ceiling }\end{array}$ \\
\hline Volume & & 11100 & 180 & & 864 & 172 & 288 \\
\hline $\begin{array}{c}\text { Geometry } \\
\text { (length/width) }\end{array}$ & & $162 / 68$ & $36 / 5$ & & $36 / 24$ & $21.5 / 8$ & $24 / 12$ \\
\hline $\begin{array}{l}\text { Average } \\
\text { customers }\end{array}$ & & 592 & 106 & 228 & 194 & 68 & 16 \\
\hline Photograph & & & & & & & $-\frac{1}{619}$ \\
\hline Interior materials & Ceilings & $\begin{array}{l}\text { Gypsum } \\
\alpha=0.3\end{array}$ & $\begin{array}{l}\text { Gypsum } \\
\alpha=0.3\end{array}$ & $\begin{array}{c}\text { Gypsum } \\
\alpha=0.3\end{array}$ & $\begin{array}{c}\text { Gypsum } \\
\alpha=0.3\end{array}$ & $\begin{array}{c}\text { Gypsum } \\
\alpha=0.3\end{array}$ & $\begin{array}{c}\text { Gypsum } \\
\alpha=0.3\end{array}$ \\
\hline $\begin{array}{l}\text { and sound } \\
\text { absorption }\end{array}$ & Walls & $\begin{array}{l}\text { Marble } \\
\alpha=0.01\end{array}$ & $\begin{array}{l}\text { Marble } \\
\alpha=0.01\end{array}$ & $\begin{array}{l}\text { Marble } \\
\alpha=0.01\end{array}$ & $\begin{array}{l}\text { Marble } \\
\alpha=0.01\end{array}$ & $\begin{array}{c}\text { Glass } \\
\alpha=0.18\end{array}$ & $\begin{array}{c}\text { Glass } \\
\alpha=0.18\end{array}$ \\
\hline coefficients & Floors & $\begin{array}{l}\text { Marble } \\
\alpha=0.01\end{array}$ & $\begin{array}{l}\text { Marble } \\
\alpha=0.01\end{array}$ & $\begin{array}{l}\text { Marble } \\
\alpha=0.01\end{array}$ & $\begin{array}{l}\text { Marble } \\
\alpha=0.01\end{array}$ & $\begin{array}{c}\text { Ceramic } \\
\alpha=0.02\end{array}$ & $\begin{array}{l}\text { Marble } \\
\alpha=0.01\end{array}$ \\
\hline $\begin{array}{c}\text { Sound } \\
\text { absorber/reflect } \\
\text { or }\end{array}$ & & Seat & $\begin{array}{l}\text { X-ray security } \\
\text { Glass } \\
\text { partition }\end{array}$ & Fare gate & $\begin{array}{c}\text { Ticket } \\
\text { machine/window }\end{array}$ & $\begin{array}{l}\text { Seat } \\
\text { Table }\end{array}$ & Partition wall \\
\hline Broadcast & & $\begin{array}{l}\text { With a } \\
\text { broadcast }\end{array}$ & $\begin{array}{c}\text { With } \\
\text { a broadcast }\end{array}$ & $\begin{array}{l}\text { With a } \\
\text { broadcast }\end{array}$ & $\begin{array}{c}\text { With } \\
\text { a broadcast }\end{array}$ & $\begin{array}{l}\text { Without } \\
\text { a } \\
\text { broadcast }\end{array}$ & $\begin{array}{c}\text { With } \\
\text { a broadcast }\end{array}$ \\
\hline $\begin{array}{l}\text { Behavioral } \\
\text { patterns }\end{array}$ & & $\begin{array}{l}\text { Talking, } \\
\text { resting }\end{array}$ & $\begin{array}{l}\text { Talking, } \\
\text { security } \\
\text { checks }\end{array}$ & $\begin{array}{l}\text { Ticket } \\
\text { checks, } \\
\text { talking, } \\
\text { walking }\end{array}$ & $\begin{array}{l}\text { Talking, ticket } \\
\text { machine use, } \\
\text { walking }\end{array}$ & $\begin{array}{l}\text { Dining, } \\
\text { walking, } \\
\text { talking }\end{array}$ & $\begin{array}{l}\text { Talking, } \\
\text { walking }\end{array}$ \\
\hline
\end{tabular}

Acoustic comfort is a key evaluation index for the soundscapes of indoor spaces [43]. Thus, this 155 study examined the influences of different spaces in the evaluation of passenger acoustic comfort 
156

157

158

159

160

161

162

163

164

165

166

167

168

169

170

171

172

173

174

175

176

177

178

179

180

181

182

183

184

185

186

187

188

189

190

191

192

193

194

195

196

using a questionnaire survey method. In this study, a total of 300 questionnaires were issued, 50 in each representative space, among which 289 were valid. The participants were of different ages and a balanced male-to-female ratio was maintained: the participants were between 15 and 80 years old, and the male-to-female ratio was set to 1.02:1 (146 males and 143 females) to ensure that the sample sex ratio was balanced.

To ensure the representativeness of the selected spaces, a preliminary survey of six typical spaces in the station was conducted before the formal investigation [30]. The contents of the investigation concerned sound sources, personnel behavior, sound field characteristics and comfort evaluation. The results obtained from the six spaces were typical and obviously diverse. Previous studies have also indicated that an interview duration of more than 5 min may decrease the reliability of the investigation [44]; therefore, the questionnaires in this study were all delivered and completed within 2-3 min. Approximately 10 interviews were conducted at each survey point. Participants were interviewed individually and briefed on the purpose of the study; then, they provided written informed consent to participate in the research. The survey points are marked with solid circles in Fig. 1, and Table 3 shows the questions, which included four social factors (Nos. 1-6) and a subjective evaluation (Nos. 7-14). Previous studies have shown that social factors may cause different evaluation results [45], and therefore, Nos. 1-4 provide a survey of the social background. When people arrive at the waiting hall at different time periods, they may give different evaluations of the comfort level of the acoustic environment. In addition, the time people spend in the space may also make a difference in their evaluation of environmental comfort. Nos. 5-6 are intended to address the above questions. Nos. 7-10 provide a subjective evaluation of the total sound environment and Nos. 11-15 provide a subjective evaluation of each sound source. No. 7 is an overall sound environment evaluation, No. 8 provides an evaluation of the comfort level, No. 9 asks the participant to evaluate the language intelligibility in the overall sound environment and thereby indirectly evaluate the level of background noise, and No. 10 provides a subjective evaluation of the reverberation time. The existing research showed that the acoustic comfort of sound sources is related to sound characteristics such as loudness, intelligibility, noise level and preference degree, as shown in Table 3, Nos. 12-15. Loudness is a subjective measurement describing the strength of the ear's perception of a sound [46]. Intelligibility is a measure of speech comprehensibility during communication [47]. Sound level refers to various logarithmic measurements of audible vibrations [48], and preference degree is related to a person's degree of preference for one or more sound sources [49].

The attitudes of participants were measured using a Likert scale, which has been widely used in survey research of environmental effects on subjective comfort [50,51]. Regarding acoustic comfort, the interviewees provided answers using the following five-point Likert-type scale: 1, very uncomfortable; 2, uncomfortable; 3, neither comfortable nor uncomfortable; 4, comfortable; and 5, very comfortable [52]. The reliability coefficient of the questionnaire was estimated as 0.82 (Cronbach's alpha). The Kaiser-Meyer-Olkin (KMO) values of the subscales were greater than 0.5. For the Bartlett spherical test, $p<0.01$, with a reliability coefficient of $0.9>\alpha \geq 0.8$, indicating that the questionnaire satisfied the reliability requirement [53].

Table 3 Questionnaire questions and scales.

\begin{tabular}{lll}
\hline No. & Questions & Scale \\
\hline 1. & Gender & 1, male; 2 , female \\
2. & Age & $1,<20 ; 2,20-40 ; 3,40-60 ; 4,>60$ \\
3. & Education level & 1, primary; 2, secondary; 3, higher education \\
4. & Income & $1,<1000 ; 2,1000-2000 ; 3,2001-3000 ; 4,3001-4000 ; 5,4001-5000 ;$ \\
& & $6,>6000$ \\
5. & Visit time & 1, morning $(9: 00-11: 59) ; 2$, midday (12:00-14:59); 3, afternoon \\
& & $(15: 00-17: 59) ; 4$, evening $(18: 00-21: 00)$ \\
\hline
\end{tabular}




\begin{tabular}{|c|c|c|}
\hline 6. & isit duration & 1, less than an $\mathrm{r}$ \\
\hline 7. & $\begin{array}{l}\text { Evaluation of the overall sound } \\
\text { environment }\end{array}$ & 1 being very noisy and 5 being very quiet \\
\hline 8 & $\begin{array}{l}\text { Acoustic comfort of the overall sound } \\
\text { environment }\end{array}$ & $\begin{array}{l}\text { scale of } 1 \text { to } 5 \text {, with } 1 \text { being very uncomfortable and } 5 \text { being very } \\
\text { comfortable }\end{array}$ \\
\hline 9. & $\begin{array}{l}\text { Sound volume of communicating with } \\
\text { companions }\end{array}$ & scale of 1 to 5 , with 1 being very loud and 5 being very soft \\
\hline 10. & $\begin{array}{l}\text { Subjective } \\
\text { reverberation }\end{array}$ & Scale of 1 to 5 , with 1 being very long and 5 being very short \\
\hline 11. & $\begin{array}{l}\text { Acoustic comfort of various sound } \\
\text { sources }\end{array}$ & $\begin{array}{l}\text { scale of } 1 \text { to } 5 \text {, with } 1 \text { being very uncomfortable and } 5 \text { being very } \\
\text { comfortable }\end{array}$ \\
\hline 12. & Loudness of various sound sources & scale of 1 to 5 , with 1 being very low and 5 being very high \\
\hline 13. & Intelligibility of various sound sources & scale of 1 to 5 , with 1 being very clear and 5 being very unclear \\
\hline 14. & Noise level of various sound sources & scale of 1 to 5 , with 1 being very noisy and 5 being very quiet \\
\hline 15. & $\begin{array}{l}\text { Preference degree of various sound } \\
\text { sources }\end{array}$ & scale of 1 to 5 , with 1 being highly disliked and 5 being highly liked \\
\hline
\end{tabular}

\subsection{Data statistics and analysis}

The results of the subjective and objective measurements were analyzed using SPSS 15.0 software [54]. Pearson's correlation coefficient was used to determine the factors and dominant sound sources that affected people's comfort evaluations of the sound environment, and mean differences (t-tests, two-tailed) were used to investigate the influences of the existence or nonexistence of dominant background sound sources on the participants. Pearson's correlation and regression analysis were used to determine the factors affecting the acoustic comfort of the dominant sound sources from the sound source characteristics. The factors affecting people's acoustic comfort evaluation are discussed from the perspectives of demographic and social factors.

\section{Results and analysis}

Based on the survey and measurement results, this section discusses the following effects: different types of sound sources, dominant sound sources, demographic and social factors on sound level, sound perception, loudness and acoustic comfort.

\subsection{0verall comfort level and sound environment}

Fig. 2 shows the subjective evaluations of the overall sound environment in the six spaces and includes the mean and standard deviation of each evaluation. The comfort of the sound environment in the railway station was acceptable (mean value of 3.65). However, the comfort evaluations in the seating area and shop were relatively higher (mean values of 3.81 and 3.91, respectively), and the comfort evaluations in the restaurant were slightly lower (mean value of 3.28). Sound level and speech intelligibility were considered the most important influencing factors in the sound environment [55]. The SPL and RT measurement results are shown in Table 4. The seating area, shop area and ticket lobby were quieter, and the areas with high concentrations of people are noisy. RT is related to the size of the space: the larger the space is, the longer the RT is. 


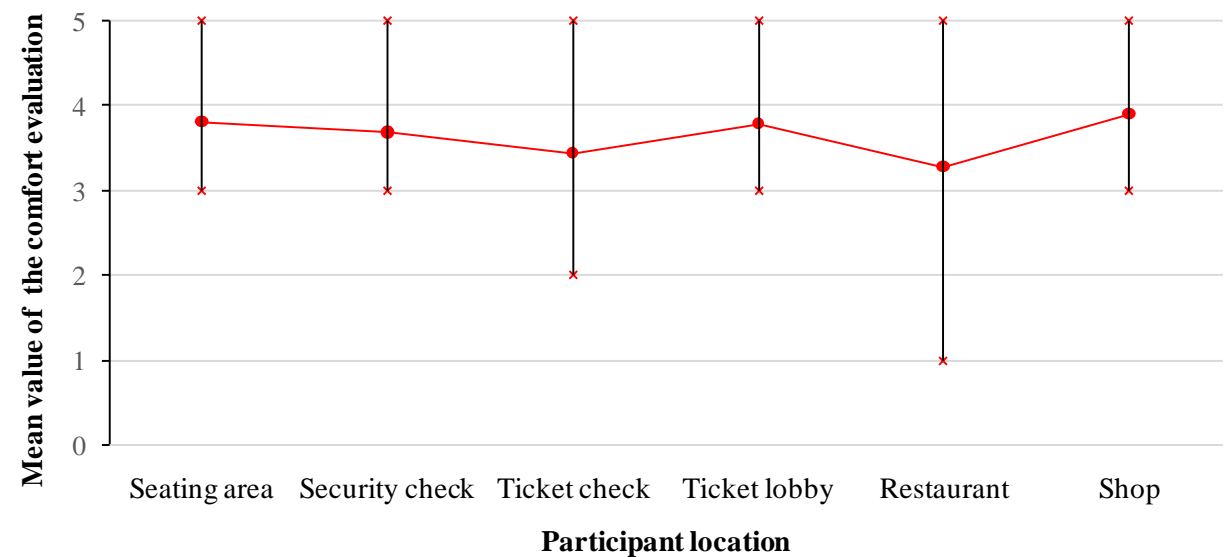

Table 4 Measurement results for each measurement point in the six areas.

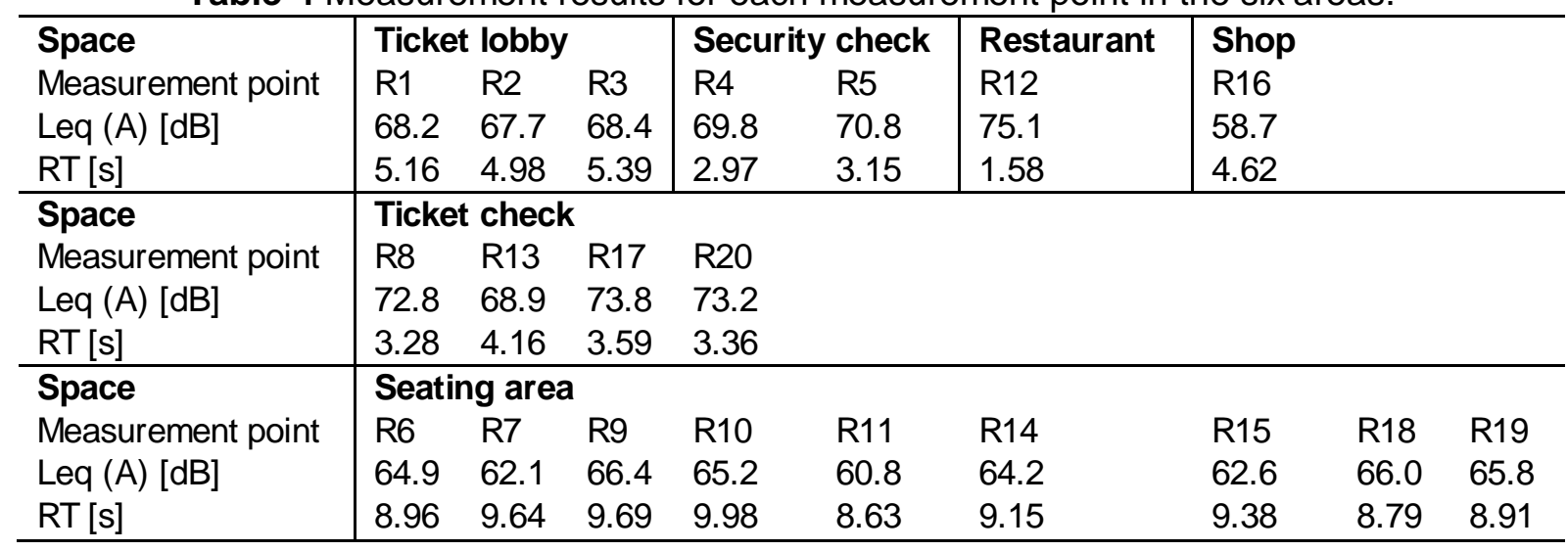

Fig. 2. Means and standard deviations of the comfort evaluations of the overall sound environment

Fig. 3 illustrates the individual response ratings regarding the overall environment vs. the SPL measurement at each survey site. The overall trend is that the comfort level and sound volume of communication decrease with increasing SPL. However, it is interesting to note that in addition to the measuring point of the restaurant, the other measuring points also show reduced comfort levels as the sound pressure level increases. The average SPL values in the seating area, ticket lobby and shops were all below $70 \mathrm{~dB}$. The restaurants are the noisiest places, with an average SPL value of $75.1 \mathrm{~dB}$, but the comfort level and the appropriateness rating in the restaurants are higher than those in the ticket check area. According to the Pearson correlation analysis, the correlation coefficient between the subjective comfort evaluation of the sound environment and the objective SPL measurement was $0.513(p<0.01)$. In other words, there is a significant positive correlation between the subjective comfort evaluation and the objective measurement of the SPL, namely, the SPL affects the comfort evaluation of the sound environment.

The ratings of the individual responses on the overall environment vs. the RT measurement at each survey site are shown in Fig. 4. It is interesting to see that as the RT increases, the comfort level also increases. When the RT exceeds $4.5 \mathrm{~s}$, participants can feel the reverberation in the space. High RT also increases the communication sound volume because high RT increases the background noise and reduces speech intelligibility [56]. 


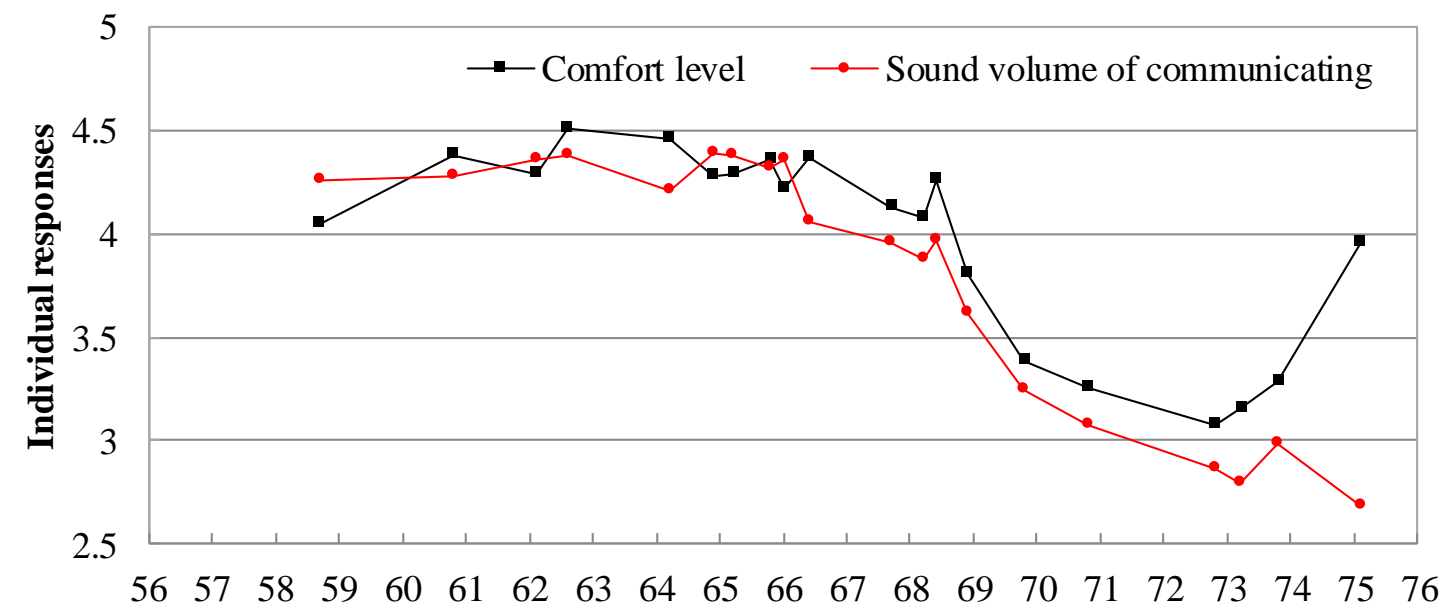

Sound pressure level $\mathrm{db}(\mathrm{A})$

Fig. 3. Ratings of the comfort level and appropriateness with mean values of the SPL measurements.

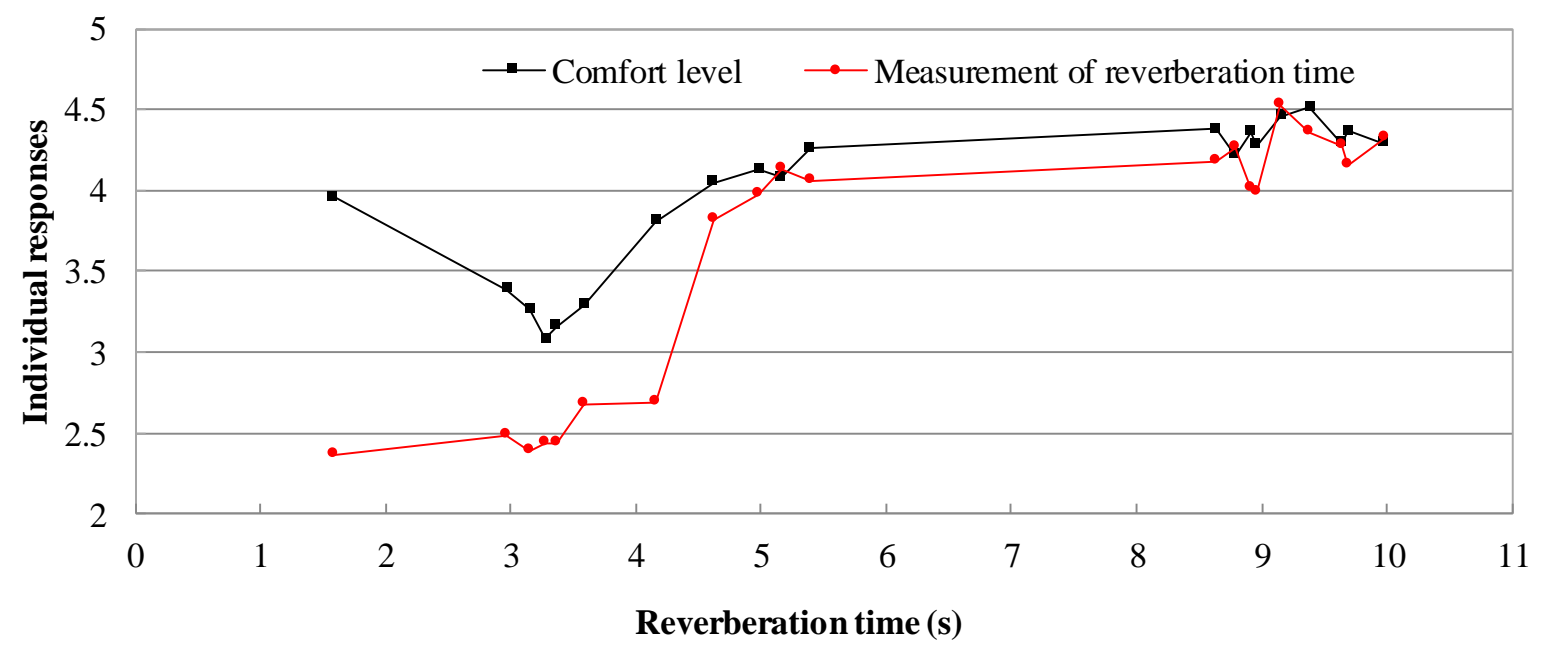

Fig. 4. Ratings of the comfort level and subjective impression of reverberation with the RT measurements

\subsection{Sonic composition}

Participants were asked to list three sounds that they heard at that moment and provide a comfort scale (scale of 1 to 5 , with 1 being very uncomfortable and 5 being very comfortable) to identify various background noise sound sources and determine the types of the sound sources from participants' perspective. Sound sources mentioned fewer than five times were ignored [57]. Finally, the various individual sound sources in railway stations were divided into five types: broadcasts, speech sounds, activity sounds, mechanical noise and luggage noise. The key sounds and comfort scale in each space are shown in Fig. 5. Interestingly, the participants gave lower evaluations of the comfort level at the survey points in spaces with high-density crowds, such as ticket checks and restaurants, and they were significantly influenced by activity sounds and speech sounds. The participants found the spaces around machines to be a generally poor acoustic environment, and it appeared that people were bothered more by mechanical noise and luggage noise. In particular, as a key sound, most participants gave a high appropriateness score for broadcasts, and people interacting and communicating in spaces were not significantly annoyed by broadcasts. 


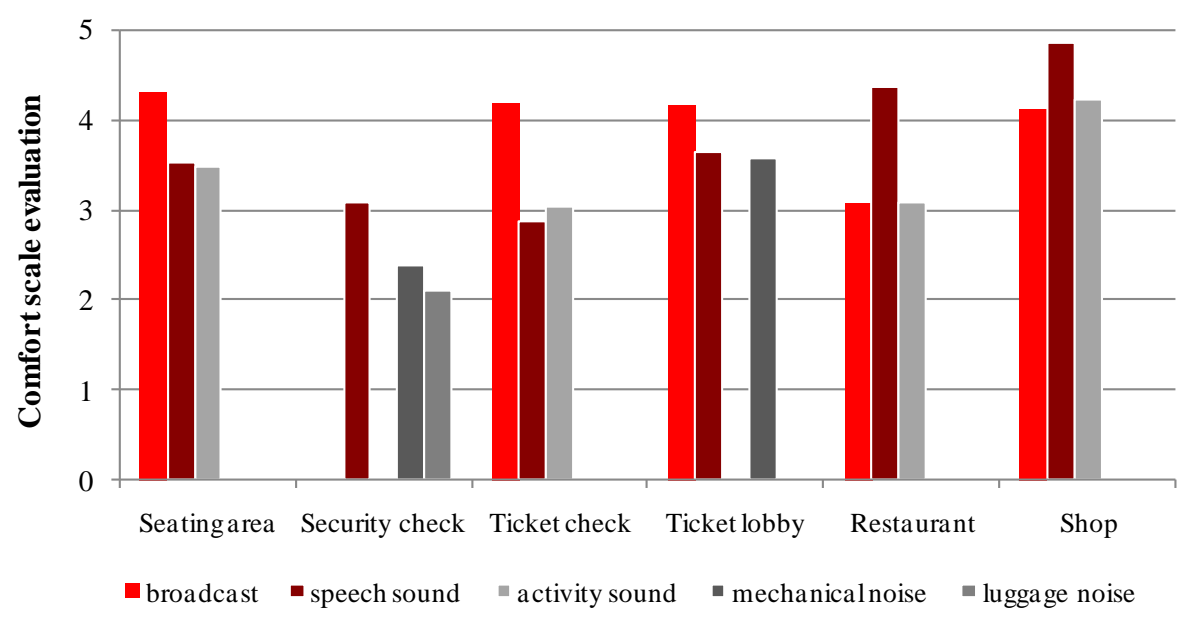

The space name of participant location

Fig. 5. Key sounds and mean comfort evaluation in different spaces

Participants were also asked to list five sound sources that they heard in each space and provide their evaluation of the acoustic comfort. Table 5 (Column A) shows the means and standard deviations of the participants' acoustic comfort evaluation of various background noise sound sources in the spaces. As a key sound, broadcasts were fundamental in most spaces. This sound did not garner much attention in the security check, but participants listed broadcasts as a key sound source in the other spaces, and the acoustic comfort evaluation of broadcasts tended to be given a comfortable score. The speech sound sources consisted of the sounds of participants (the speech sounds of companions and other participants, shouting, crying and phone calls of people moving around) and the speech sounds of staff. Speech sounds were mentioned as key sounds in every space, and the participants tended to provide a better evaluation of the comfort level of speech sounds in commercial spaces, including restaurants and shops. The comfort level of speech sound was the lowest in the ticket check area and was evaluated as uncomfortable. A comparison of the measurement results of the SPL found that the SPLs of the test points R8, R17 and R20 near the ticket check all exceeded $70 \mathrm{~dB}$, indicating that when an SPL is above a certain level enhances the annoyance degree of speech sound, resulting in low comfort-level evaluations in this area. Activity sound sources were caused by user activities in these spaces, including impact sounds from footsteps, scratching sounds from clothes, the sounds of food preparation by staff, and the sounds of people choosing goods from store shelves. Participants listed activity sounds as dominant in the seating and ticket check areas and in restaurants and shops. The general evaluation of its comfort level showed more comfort in shops. Mechanical noise sources include the sounds of a ticket machine, the sounds of a security check machine, the sounds of a ticket check machine, and the sounds of ventilators and elevators. In the security check area, mechanical noise was evaluated as an uncomfortable sound source; however, in the ticket lobby, the mechanical noise was considered acceptable. Luggage noise sources included the sounds of dragging luggage and placing luggage in the security scan machine. Luggage noise was listed as a key sound only in the security check area and was evaluated as an uncomfortable sound source.

Table 5 provides a statistical analysis using the Pearson correlation of the acoustic comfort evaluations of various individual sound sources and the comfort evaluation of the overall sound environment in each space $(p<0.01)$. The results showed that positive correlations among the following: acoustic comfort evaluations of broadcast sounds, the speech sounds of other participants, and shouting in the seating area; the speech sounds of the staff, the security check machine and the sound of placing luggage in the security scan machine in security check area; broadcast sounds, conversational sounds from other participants and the sound of the ticket machine in the ticket lobby; the speech sounds of staff and the food preparation by staff in the restaurant; and the broadcast and the chatting sounds of other participants in the shops. The 
301 correlation coefficients ranged from 0.25-0.5. To determine the influences of these sound sources 302 on the overall comfort of the sound environment, an independent samples t-test was conducted in 303 both the presence and absence of the sound sources. The results (Table 4, Column C) showed 304 that the comfort evaluations of the overall sound environment in the presence or absence of 305 shouting in the seating area, luggage noise in the security check, the speech sounds of staff at the 306 ticket check and shouting in the ticket lobby all displayed marked differences. The comfort 307 evaluation (mean of 2.96) of the overall sound environment in the seating area in the presence of 308 shouting was significantly lower than that (mean of 3.42) in the absence of shouting; the comfort 309 evaluation (mean value of 2.11) of the overall sound environment in the security check in the 310 presence of luggage noise was lower than that (mean of 2.69) in the absence of luggage noise; the 311 comfort evaluation (mean of 2.49) of the overall sound environment in the ticket check in the 312 presence of the speech sounds of staff was lower than that (mean of 2.92) in the absence of the 313 speech sounds of staff; and the comfort evaluation (mean of 3.01) of the overall sound environment 314 in the ticket lobby in the presence of shouting was lower than that (mean of 3.42) in the absence 315 of shouting. The presence or absence of broadcast and chatting sounds of other participants in the 316 seating area; the speech sounds of staff and security check machines in the security check; the 317 broadcast and chatting sounds of other participants in the ticket check; the broadcast and ticket 318 machine noise in the ticket lobby; the speech sounds of staff and food preparation by staff in 319 restaurants; and the broadcast and chatting sounds of other participants in shops showed no 320 significant effect on the comfort evaluation of the overall sound environment.

321 Table 5. Correlation analysis between the acoustic comfort of various sound sources and the overall sound

\begin{tabular}{|c|c|c|c|c|c|}
\hline $\begin{array}{l}\text { Name of } \\
\text { space }\end{array}$ & $\begin{array}{l}\text { Type of sound source } \\
\text { (Only include key sound } \\
\text { sources) }\end{array}$ & & $\mathbf{A}$ & B & C \\
\hline \multirow[t]{5}{*}{ Seating area } & Broadcast & Broadcast information & $4.31 / 0.68$ & $0.293 / 0.000\left(^{* \star}\right)$ & $\begin{array}{c}P=0.072> \\
0.05\end{array}$ \\
\hline & Speech sounds & Speech sounds of companions & $4.02 / 0.81$ & $0.223 / 0.021$ & 1 \\
\hline & & Chatting sounds of other people & $3.97 / 1.05$ & $0.492 / 0.000\left(^{* \star}\right)$ & $\begin{array}{c}\mathrm{P}=0.075> \\
0.05\end{array}$ \\
\hline & & Shouting & $2.96 / 0.80$ & $0.228 / 0.000\left(^{* *}\right)$ & $\begin{array}{c}\mathrm{P}=0.035< \\
0.05\end{array}$ \\
\hline & & Crying & $3.08 / 0.89$ & $0.245 / 0.037$ & l \\
\hline \multirow[t]{5}{*}{ Security check } & Speech sounds & Speech sounds of companions & $3.56 / 0.86$ & $0.198 / 0.026$ & 1 \\
\hline & & Chatting sounds of other people & $3.01 / 0.88$ & $0.312 / 0.053$ & 1 \\
\hline & & Speech sounds of staff & $2.86 / 0.89$ & $0.332 / 0.000\left(^{\star *}\right)$ & $\begin{array}{c}\mathrm{P}=0.081> \\
0.05\end{array}$ \\
\hline & Mechanical noise & Security check machines & $2.39 / 0.93$ & $0.255 / 0.000\left(^{* \star}\right)$ & $\begin{array}{c}\mathrm{P}=0.093> \\
0.05\end{array}$ \\
\hline & Luggage noise & Placement of luggage & $2.11 / 0.69$ & $0.366 / 0.000\left(^{\star *}\right)$ & $\begin{array}{c}\mathrm{P}=0.035< \\
0.05\end{array}$ \\
\hline \multirow[t]{5}{*}{ Ticket check } & Broadcast & Broadcast information & $4.18 / 1.02$ & $0.258 / 0.000\left({ }^{* \star}\right)$ & $\begin{array}{c}\mathrm{P}=0.065> \\
0.05\end{array}$ \\
\hline & Speech sounds & Speech sounds of companions & $3.29 / 0.87$ & $0.218 / 0.041$ & 1 \\
\hline & & Chatting sounds of other people & $2.98 / 0.82$ & $0.308 / 0.000(* *)$ & $\begin{array}{c}\mathrm{P}=0.072> \\
0.05\end{array}$ \\
\hline & & Speech sounds of staff & $2.49 / 0.79$ & $0.281 / 0.000\left(^{\star \star}\right)$ & $\begin{array}{c}\mathrm{P}=0.035< \\
0.05\end{array}$ \\
\hline & & Shouting & $2.36 / 0.83$ & $0.186 / 0.044$ & 1 \\
\hline \multirow[t]{5}{*}{ Ticket lobby } & Broadcast & Broadcast information & $4.16 / 0.92$ & $0.292 / 0.000\left(^{* *}\right)$ & $\begin{array}{c}P=0.064> \\
0.05\end{array}$ \\
\hline & Speech sounds & Speech sounds of companions & $3.87 / 0.83$ & $0.124 / 0.128$ & 1 \\
\hline & & Chatting sounds of other people & $3.49 / 0.69$ & $0.146 / 0.013$ & 1 \\
\hline & & Shouting & $3.01 / 0.78$ & $0.322 / 0.000(* \star)$ & $\begin{array}{c}\mathrm{P}=0.035< \\
0.05\end{array}$ \\
\hline & Mechanical noise & Ticket machines & $3.56 / 0.96$ & $0.251 / 0.000(* *)$ & $\begin{array}{c}P=0.082> \\
0.05\end{array}$ \\
\hline \multirow[t]{4}{*}{ Restaurant } & Broadcast & Broadcast information & $3.08 / 0.85$ & $0.243 / 0.029$ & 1 \\
\hline & Speech sounds & Speech sounds of companions & $4.47 / 0.92$ & $0.242 / 0.086$ & 1 \\
\hline & & Chatting sounds of other people & $4.27 / 1.01$ & $0.262 / 0.069$ & 1 \\
\hline & & Speech sounds of staff & $4.36 / 1.14$ & $0.265 / 0.000\left({ }^{* *}\right)$ & $\begin{array}{c}\mathrm{P}=0.095> \\
0.05\end{array}$ \\
\hline
\end{tabular}


Yue Wu, Jian Kang, Wenzhong Zheng, Yongxiang Wu: Applied Acoustics

https://doi.org/10.1016/j.apacoust.2019.107137

\begin{tabular}{|c|c|c|c|c|c|}
\hline & Activity sounds & Food preparation by staff & $3.08 / 0.96$ & $0.278 / 0.000\left(^{\star \star}\right)$ & $\begin{array}{c}P=0.068> \\
0.05\end{array}$ \\
\hline \multirow[t]{5}{*}{ Shop } & Broadcast & Broadcast information & $4.12 / 0.98$ & $0.226 / 0.000\left(^{* *}\right)$ & $\begin{array}{c}\mathrm{P}=0.089> \\
0.05\end{array}$ \\
\hline & Speech sounds & Speech sounds of companions & $4.95 / 0.82$ & $0.206 / 0.028$ & 1 \\
\hline & & Chatting sounds of other people & $4.78 / 0.99$ & $0.288 / 0.000\left(^{* \star}\right)$ & $\begin{array}{c}P=0.091> \\
0.05\end{array}$ \\
\hline & & Speech sounds of staff & $4.82 / 0.83$ & $0.186 / 0.058$ & 1 \\
\hline & Activity sounds & $\begin{array}{l}\text { Choosing goods from store } \\
\text { shelves }\end{array}$ & $4.22 / 0.79$ & $0.229 / 0.083$ & / \\
\hline
\end{tabular}

A. Mean and standard deviation of the acoustic comfort evaluations of the sound sources

B. Correlation coefficient and significance level of acoustic comfort evaluation of various sound sources and the overall sound environment comfort evaluation

C. P-value of independent samples t-test

\subsection{Sound characteristics of dominant individual sound sources}

In this section, the subjective evaluations of the loudness, intelligibility, noise level and preference degree based on the questionnaire survey are analyzed. Fig. 6 summarizes the sound source characteristics by averaging the scores of four factors for different sound sources. Broadcasts, which drew people's attention, exhibited the lowest sound level, resulting in a high preference degree (with a mean value of 4.21), although the loudness and intelligibility were high. However, there were variations in the luggage noise and mechanical noise; they had a high sound level and loudness but a low preference degree, meaning that these two sound sources resulted in a high annoyance degree (discomfort) of people (means of 2.65 and 2.54, respectively). The four sound characteristics of speech and activity sounds were moderate, with mean values of 3-4.

Sound sources characteristics

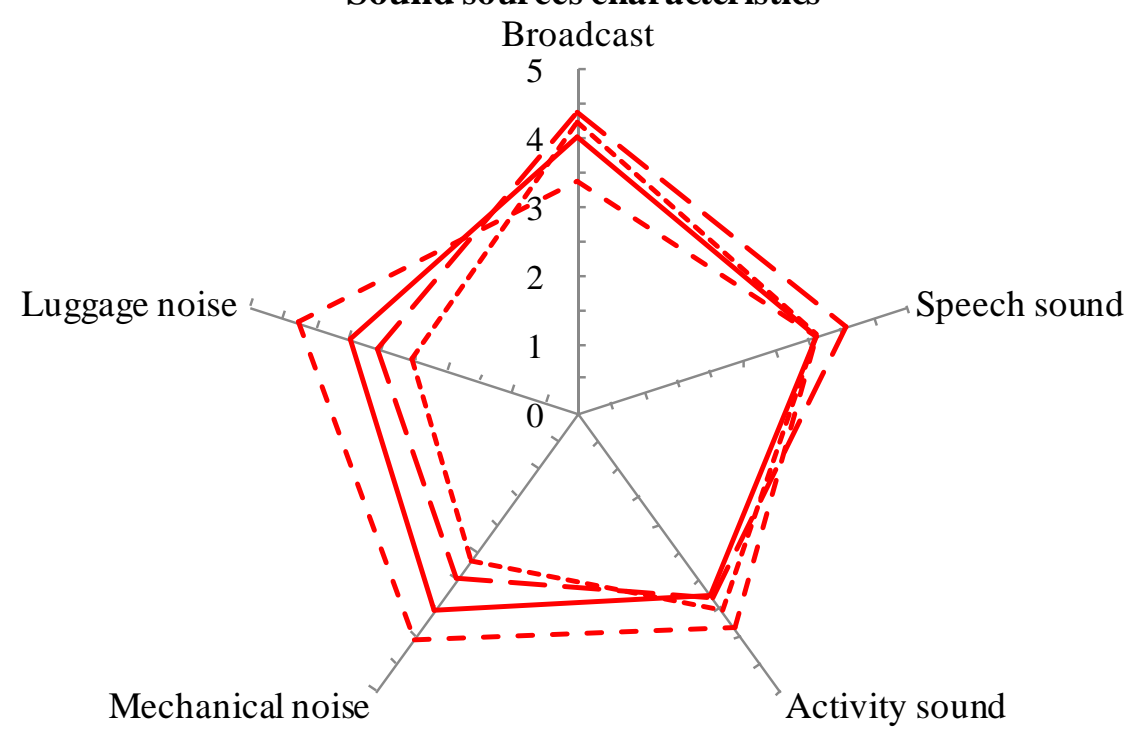

Fig. 6. Sound source characteristics for each sound source.

Because the evaluation of the sound characteristics of the dominant sound sources may have different influences on the SPL and acoustic comfort, the SPLs and acoustic comfort of different sound source characteristics from different dominant sound sources were also compared. Mechanical noise and luggage noise are not analyzed in this section due to a lack of examples. The relationships between the measured LAeq and sound source characteristics as well as acoustic comfort and sound source characteristics with different sound sources are shown in Figs. 7-8, where the linear regressions and the coefficients of determination $\left(R^{2}\right)$ are also presented. There is a general correlation between the measured sound level and loudness and intelligibility as well as with the sound level for some of the sound sources $(p<0.001)$.

As the measured overall sound level increases, the sound level of speech also increased; the $R^{2}$ 
value was 0.515 . Other sound sources showed only weak correlations. A possible reason for this difference is that broadcasts and activity sounds were not always present, but speech sounds were always present as background noise, and noise from speech was the most important factor affecting the sound environment. It is interesting to note that as the measured sound level increased, the intelligibility of both the broadcast and speech sound also decreased; the $R^{2}$ values were 0.511 (broadcast) and 0.532 (speech sound). A possible reason is that the increase in the SPL is mainly caused by these two sounds; they interfere with each other such that one voice obscures the other, decreasing the intelligibility of both. It is also interesting to note that as the measured sound level increased, the loudness of three sound sources decreased; sound masking among these sound sources may have led to this result. There was a significant correlation $\left(R^{2}=\right.$ 0.791 ) between acoustic comfort and the speech sound level, indicating that noise from speech sounds is not generally liked.
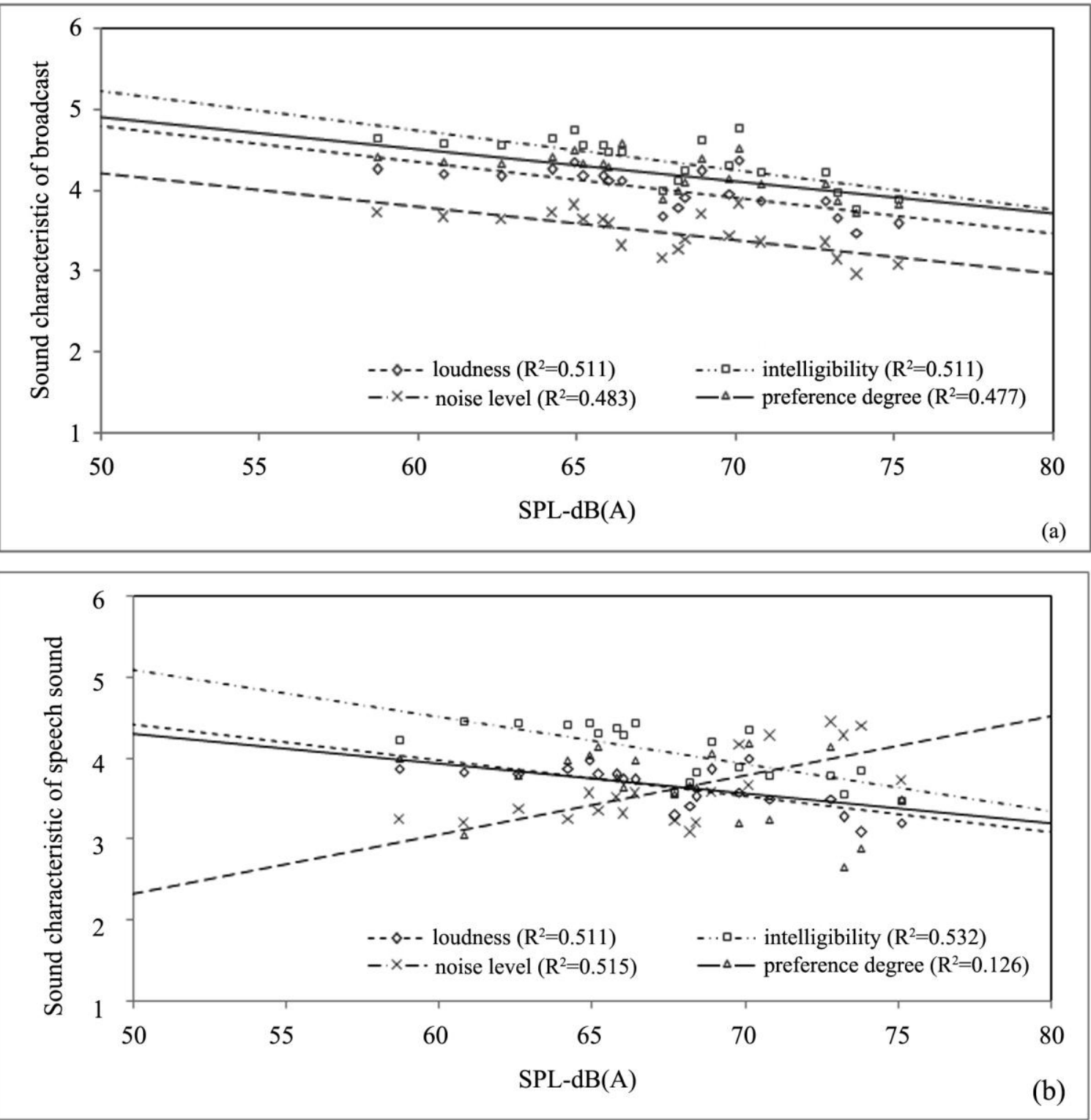


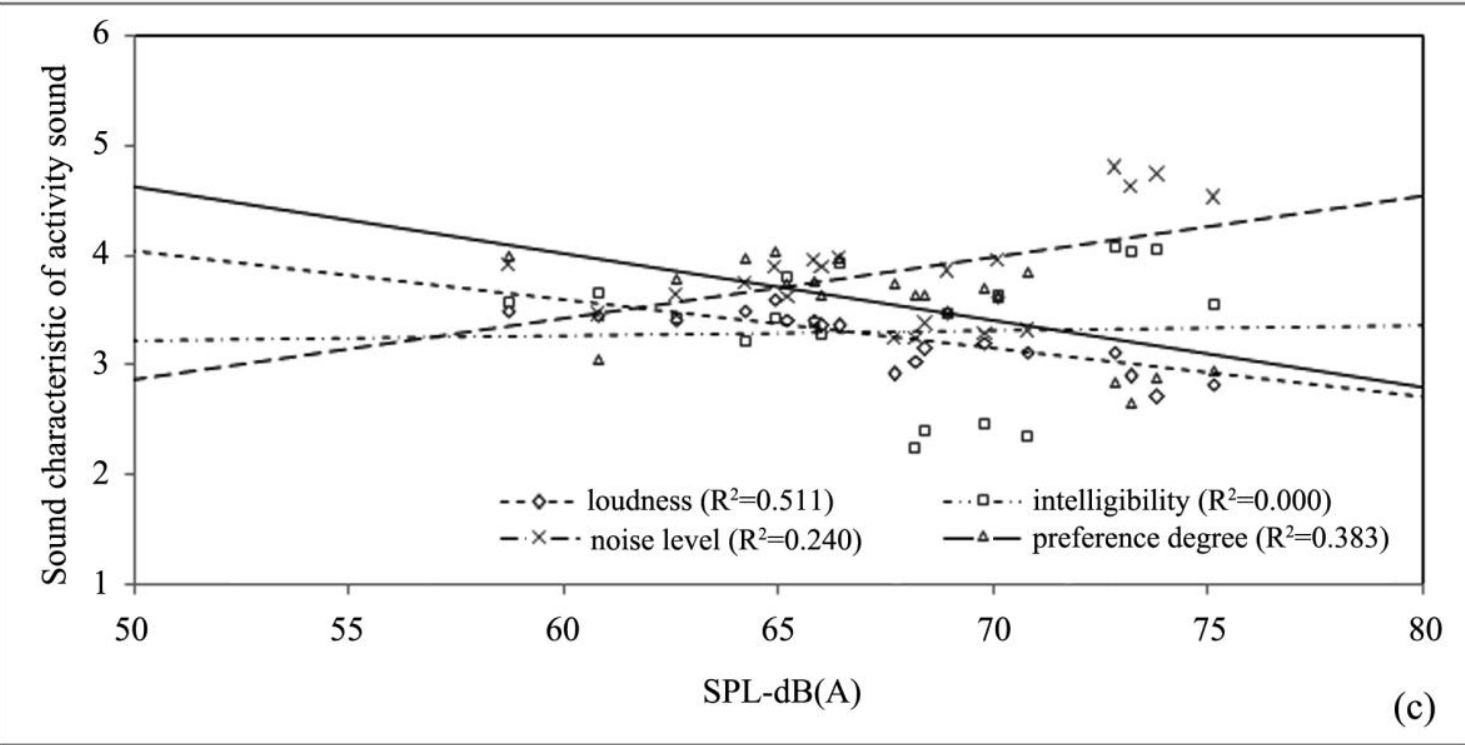

Fig. 7. The relationship between SPL and the sound characteristics of the dominant sound sources.

(a) Relationship between SPL and the sound characteristics of a broadcast;

(b) Relationship between SPL and the sound characteristics of speech sounds;

(c) Relationship between SPL and the sound characteristics of activity sounds.

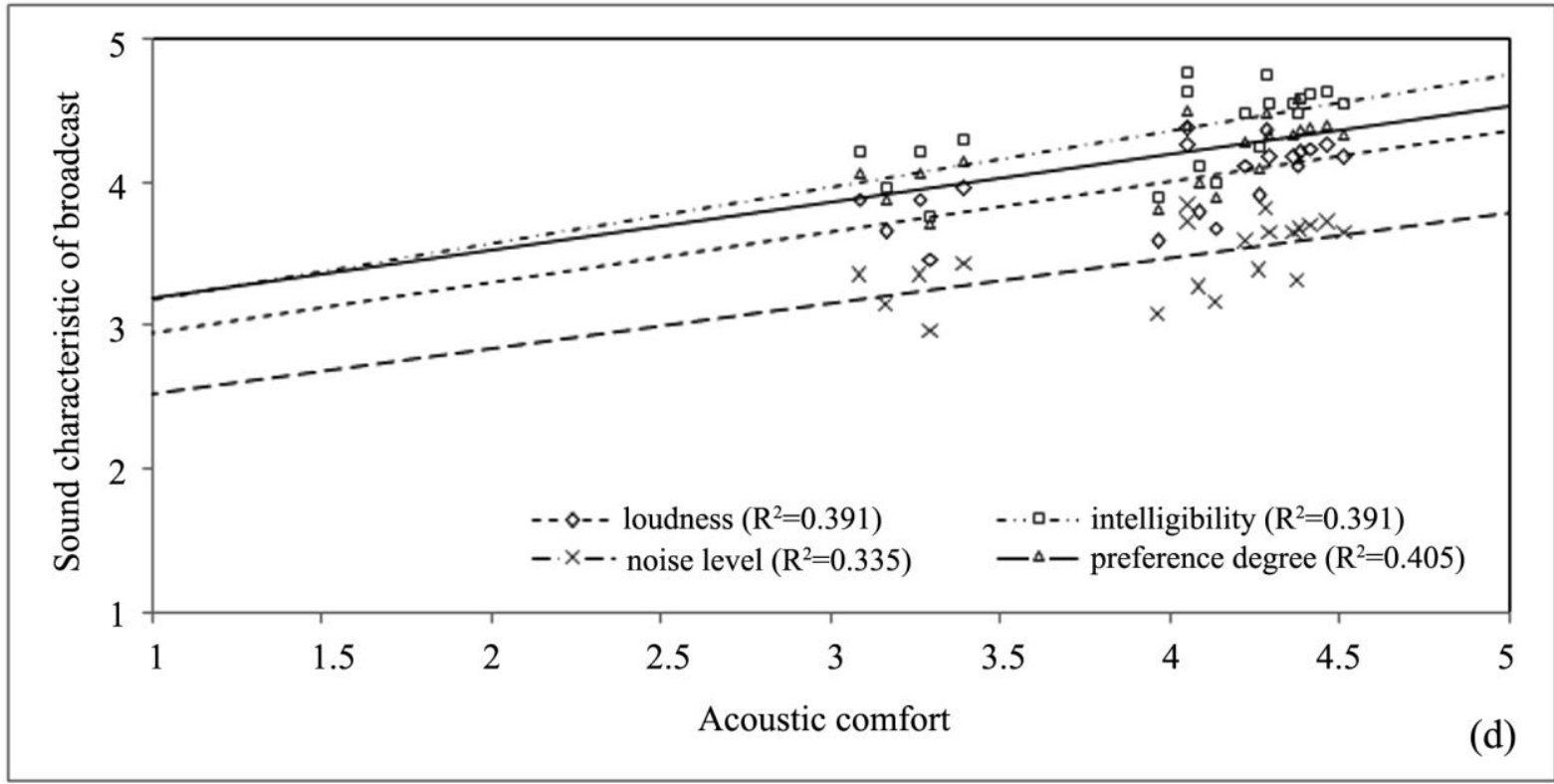



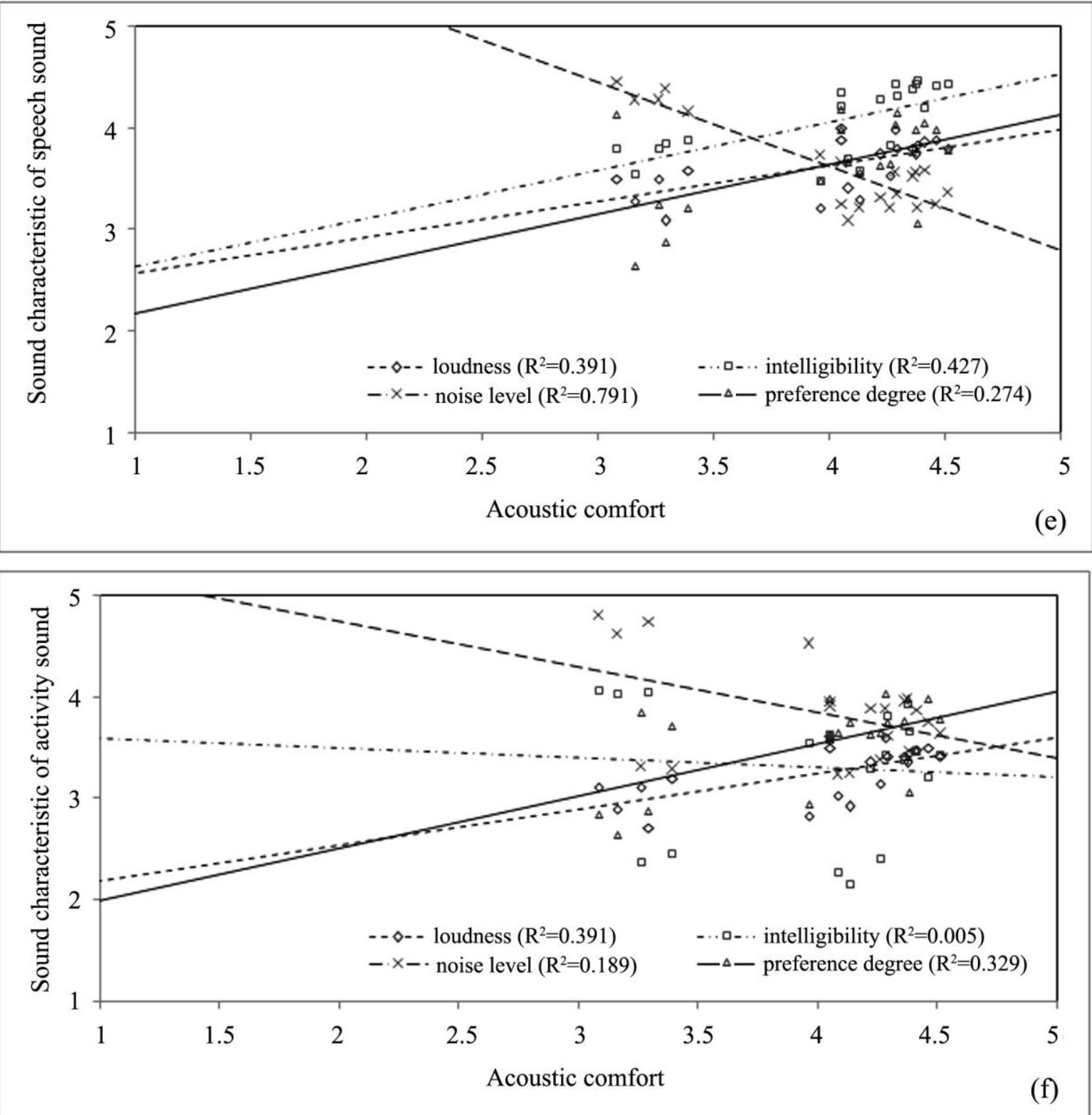

Fig. 8. The relationship between acoustic comfort and the sound characteristics of the dominant sound sources.

(a) Relationship between acoustic comfort and the sound characteristics of a broadcast;

(b) Relationship between acoustic comfort and the sound characteristic of speech sounds;

(c) Relationship between acoustic comfort and the sound characteristics of activity sounds.

\subsection{Effects of demographic and social factors}

The mean difference between males and females in the evaluation of acoustic comfort was determined in every space. As shown in Table 6 , no significant differences $(p<0.1)$ were found between males and females. These results were consistent with those of previous studies, which suggested that the effect of gender on sound annoyance evaluation is generally insignificant (Meng and Kang, 2016). However, age difference was significant $(p<0.01$ or $p<0.05)$; the correlation coefficients ranged from 0.16 to 0.28 in most spaces. Acoustic comfort was higher for older people, and our results are consistent with those of a previous study in Europe [1], which showed that cultural aspects were not the main factor influencing older people's noise perceptions. The same conclusion has been drawn for other types of buildings [58]. Education level and income difference were also significant factors $(p<0.01$ or $p<0.05)$ in people's acoustic comfort; the correlation coefficients ranged from 0.13 to 0.22 for education level and 0.15 to 0.22 for income 
390 for the tested spaces. It is interesting to note that acoustic comfort increased with higher education 391 level and income in quiet places (where the measurement results of SPL were below $70 \mathrm{~dB}$ ), while 392 it usually decreased with higher education level and income in noisy places (where the 393 measurement results of SPL exceeded $70 \mathrm{~dB}$ ). This result indicates that people with different 394 income levels have different tolerances for different SPLs. Differences in visit frequency were 395 associated with a significant difference in the comfort evaluation of the sound environment in six 396 spaces $(p<0.05)$ : people who visited the station frequently (mean $=3.46$ ) gave a more critical 397 evaluation than people who did not (mean =3.12). It was also found that the visit duration in space 398 was significantly correlated $(p<0.01)$ with acoustic comfort, and under a high SPL, visit duration 399 and acoustic comfort had a significant negative correlation. This indicates that people tend to be 400 more annoyed when they spend more time in a high-SPL environment.

Table 6. The relationship between acoustic comfort and participant demographic information.

\begin{tabular}{|c|c|c|c|c|c|c|}
\hline $\begin{array}{c}\text { Social } \\
\text { factors }\end{array}$ & $\begin{array}{c}\text { Seating } \\
\text { area }\end{array}$ & $\begin{array}{c}\text { Security } \\
\text { check }\end{array}$ & $\begin{array}{l}\text { Ticket } \\
\text { check }\end{array}$ & $\begin{array}{l}\text { Ticket } \\
\text { lobby }\end{array}$ & $\begin{array}{c}\text { Restauran } \\
t\end{array}$ & Shop \\
\hline Sex & 0.03 & 0.03 & 0.01 & 0.04 & 0.01 & 0.02 \\
\hline Age & $0.28^{\star \star}$ & $0.16^{\star}$ & $0.18^{*}$ & $0.20^{\star *}$ & $-0.15^{\star}$ & 0.08 \\
\hline $\begin{array}{l}\text { Education } \\
\text { level }\end{array}$ & $0.18^{*}$ & $-0.16^{*}$ & $-0.22^{\star \star}$ & $0.15^{\star}$ & $-0.13^{\star}$ & $0.21^{\star *}$ \\
\hline Income & $0.22^{\star \star}$ & $-0.19^{\star \star}$ & $-0.25^{\star \star}$ & $0.15^{\star}$ & 0.06 & $0.24^{\star \star}$ \\
\hline Visit time & $-0.18^{*}$ & $-0.21^{\star \star}$ & $-0.26^{\star \star}$ & $0.20^{\star *}$ & $0.15^{\star}$ & $-0.29^{\star *}$ \\
\hline Visit duration & $0.15^{\star \star}$ & $-0.28^{\star \star}$ & $-0.31^{\star \star}$ & $0.16^{\star \star}$ & $0.11^{\star *}$ & $-0.16^{\star \star}$ \\
\hline
\end{tabular}

Significant correlations are marked in bold; ${ }^{* *}$ denotes $p<0.01$ and ${ }^{*}$ denotes $p<0.05$.

\section{Conclusions}

Based on measurements and the results of a questionnaire survey conducted at a railway station, the effects of various sound sources on the sound environment and the corresponding subjective evaluations of acoustic comfort were studied.

With regard to the overall sound environment and comfort level, according to the measurement and survey results, the SPLs were concentrated between 60-70 $\mathrm{dB}(\mathrm{A})$. There was a significant positive correlation between the subjective comfort evaluation and sound level measurement: the correlation coefficient was 0.513 ( $p<0.01$ ). The comfort level and appropriateness were moderately negatively correlated with the SPL at the station. It is interesting to see that people's comfort level increases with increasing RT, which is contrary to popular belief. This result occurs because the test points with lower SPL values have longer RT, and the comfort level is more highly affected by SPL, leading to a higher comfort rating. The RT was difficult for people to sense; when it exceeded $4.5 \mathrm{~s}$, the participants could feel the reverberation in the space. High RT also increases the sound volume during communication.

The sonic composition of sound sources in the railway station included broadcasts, speech sounds, activity sounds, mechanical noise and luggage noise. The dominant sound sources differed in each space. Broadcasts, speech sounds, and activity sounds were the sounds most identified by the participants. The acoustic comfort of broadcasts was the most preferable; speech sounds were preferred in restaurants and shops but considering annoying in security and ticket check areas, and the acoustic comfort of mechanical noise and luggage noise was the least preferable in security check areas. Among the sound sources, the speech sounds of other people in the seating area, the speech sounds of staff, the sounds of placing luggage in the security scan machine in the security check area, the sound of the ticket machine in the ticket lobby, and the speech sounds of staff in the restaurants significantly influenced the participants' acoustic comfort evaluations.

With regard to the effects of various sound sources on the comfort level, the sound characteristics of five main sound sources were analyzed. The results show that people have the 
430 highest preference for broadcasts, followed by speech sounds and activity sounds. The 431 intelligibility of broadcasts is low because they are easily obscured by other sound sources, such the intelligibility of the broadcasts needs to be improved. Although the participants' preferences for speech sound and activity sound were at high levels, as the density of people increases, the preferences for those types of sound decline rapidly. Therefore, those two sound source types need to be controlled, especially in large spaces with high population densities. People dislike luggage and mechanical sounds because of their high sound levels and perceived loudness; these two sound sources received considerable attention and need to be reduced. To improve the acoustic environment, sound sources with both low preferences and high loudness were considered. It is worth investigating the sound environment of large railway stations from a soundscape perspective to determine whether measures might be implemented that would enhance users' acoustic comfort.

With regard to demographic and social factors, age differences resulted in significant differences in comfort evaluations: older people provided higher comfort evaluations. People's education level and income differences also resulted in significant differences $(p<0.01$ or $p<0.05)$ in acoustic comfort: higher incomes and education levels were associated with high evaluations of acoustic comfort in quiet places but low evaluations in noisy places. Both visit frequency and visit duration were significantly different: people who visited the station frequently gave a more critical evaluation, and visit duration and acoustic comfort had a significantly negative correlation.

While in this study the station spaces are rather large, it is also interesting to consider other spaces types such as long spaces in further studies [59-62].

\section{Acknowledgements}

The work is financially supported by the National Natural Science Foundation of China (NSFC) (51878210, 51808160).

\section{References}

[1] Y.Wu, J.Kang. The complexity of sound environment contributing to acoustic comfort in urban intermodal transit spaces. INTER-NOISE and NOISE-CON Congress and Conference Proceedings, InterNoise19, Madrid, Spain, pages 1-995, pp. 257-264(8).

[2] Weston A. The Soundscape: Our Sonic Environment and the Tuning of the World. Environmental Ethics, 1996, 18(3): 331-333. DOI: 10.5840/enviroethics199618324

[3] Huang L, Zhu Y, Ouyang Q, et al. A study on the effects of thermal, luminous, and acoustic environments on indoor environmental comfort in offices. Building and Environment, 2012, 49: 304-309. https://doi.org/10.1016/j.buildenv.2011.07.022

[4] Chen X, Kang J. Acoustic comfort in large dining spaces. Applied Acoustics, 2017, 115: 166-172. https://doi.org/10.1016/j.apacoust.2016.08.030

[5] Xiao J, Aletta F. A soundscape approach to exploring design strategies for acoustic comfort in modern public libraries: A case study of the Library of Birmingham. Noise Mapping, 2016, 3(1): 264-273. DOI 10.1515/noise-2016-0018

[6] Meng Q, Jin H, Kang J. Prediction of subjective loudness in underground shopping streets using artificial neural networks. Noise Control Engineering Journal, 2012, 60(3): 329-339. https://doi.org/10.3397/1.3701010

[7] Cassina L, Fredianelli L, Menichini I, et al. Audio-visual preferences and tranquillity ratings in urban areas[J]. Environments, 2018, 5(1): 1. https://doi.org/10.3390/environments5010001

[8] De Coensel B, Botteldooren D. The quiet rural soundscape and how to characterize it. Acta Acustica united with Acustica, 2006, 92(6): 887-897.

[9] Ruiz-Padillo A, Ruiz D P, Torija A J, et al. Selection of suitable alternatives to reduce the environmental impact of road traffic noise using a fuzzy multi-criteria decision model. Environmental Impact Assessment Review, 2016, 61: 8-18. https://doi.org/10.1016/j.eiar.2016.06.003 
479 [10] Licitra G, Fredianelli L, Petri D, et al. Annoyance evaluation due to overall railway noise and vibration in

480 Pisa urban areas. Science of the total environment, 2016, 568: 1315-1325. 481 https://doi.org/10.1016/j.scitotenv.2015.11.071

482 [11] Gagliardi P, Fredianelli L, Simonetti D, et al. ADS-B system as a useful tool for testing and redrawing 483 noise management strategies at Pisa Airport. Acta Acustica united with Acustica, 2017, 103(4): 543-551. 484 https://doi.org/10.3813/AAA.919083

485 [12] Bernardini M, Fredianelli L, Fidecaro F, et al. Noise Assessment of Small Vessels for Action Planning in 486 Canal Cities. Environments, 2019, 6(3): 31. https://doi.org/10.3390/environments6030031

487 [13] Tavossi H M. Traffic noise attenuation by scattering, resonance and dispersion. The Journal of the 488 Acoustical Society of America, 2003, 114(4): 2353-2353. https://doi.org/10.1121/1.4781158

489 [14] Makarewicz R, Żółtowski M. Variations of road traffic noise in residential areas. The Journal of the 490 Acoustical Society of America, 2008, 124(6): 3568-3575. https://doi.org/10.1121/1.3008003

491 [15] Williams I D, McCrae I S. Road traffic nuisance in residential and commercial areas. Science of the 492 total environment, 1995, 169(1-3): 75-82. https://doi.org/10.1016/0048-9697(95)04635-E

493 [16] Stansfeld S A, Berglund B, Clark C, et al. Aircraft and road traffic noise and children's cognition and 494 health: a cross-national study. The Lancet, 2005, 365(9475): 1942-1949. 495 https://doi.org/10.1016/S0140-6736(05)66660-3

496 [17] Iglesias-Merchan C, Diaz-Balteiro L, Soliño M. Transportation planning and quiet natural areas 497 preservation: Aircraft overflights noise assessment in a National Park. Transportation Research Part D: 498 Transport and Environment, 2015, 41: 1-12. https://doi.org/10.1016/j.trd.2015.09.006

499 [18] Casazza M, Boggia F, Serafino G, et al. Environmental Impact Assessment of An Urban Port: Noise 500 Pollution Survey in the Port Area of Napoli (S Italy). Journal of Environmental Accounting and Management, $501 \quad 2018,6(2): 125-133$. DOI: 10.5890/JEAM.2018.06.004.

502 [19] Babisch W, Houthuijs D, Pershagen G, et al. Associations between road traffic noise level, road traffic 503 noise annoyance and high blood pressure in the HYENA study. Journal of the Acoustical Society of 504 America, 2008, 123(5): 3448-3448.

[20] Hatano M. Noise impact of rail passenger service[C]//INTER-NOISE and NOISE-CON Congress and Conference Proceedings. Institute of Noise Control Engineering, 1982, 1982(2): 201-204.

[21] Fyhri A, Aasvang G M. Noise, sleep and poor health: Modeling the relationship between road traffic noise and cardiovascular problems. Science of the Total Environment, 2010, 408(21): 4935-4942. https://doi.org/10.1016/j.scitotenv.2010.06.057.

[22] Klatte M, Meis M, Sukowski $\mathrm{H}$, et al. Effects of irrelevant speech and traffic noise on speech perception and cognitive performance in elementary school children. Noise and Health, 2007, 9(36): 64.

[23] Münzel T, Gori T, Babisch W, et al. Cardiovascular effects of environmental noise exposure. European heart journal, 2014, 35(13): 829-836. https://doi.org/10.1093/eurheartj/ehu030.

[24] Clark C, Martin R, Van Kempen E, et al. Exposure-effect relations between aircraft and road traffic noise exposure at school and reading comprehension: the RANCH project. American journal of epidemiology, 2005, 163(1): 27-37. https://doi.org/10.1093/aje/kwj001.

[25] Stansfeld S A, Matheson M P. Noise pollution: non-auditory effects on health. British medical bulletin, 2003, 68(1): 243-257. https://doi.org/10.1093/bmb/ldg033.

[26] Wang $\mathrm{C}, \mathrm{Ma} \mathrm{H}, \mathrm{Wu} \mathrm{Y}$, et al. Characteristics and prediction of sound level in extra-large spaces. Applied Acoustics, 2018, 134: 1-7. https://doi.org/10.1016/j.apacoust.2017.12.023.

[27] Myers T D, Balmer N J. The impact of crowd noise on officiating in Muay Thai: achieving external validity in an experimental setting. Frontiers in psychology, 2012, 3: 346.

[28] Hayne M J, Taylor J C, Rumble R H, et al. Prediction of noise from small to medium sized crowds. Proceedings of Acoustics 2011, 2011.

[29] Nie S S, Kang J. An acoustic model of crowd in large spaces. Journal of Applied Acoustic, 2016, 35(2): 128-136. (in Chinese).

[30] Wu Y, Kang J, Zheng W. Acoustic environment research of railway station in China. Energy Procedia, 2018, 153: 353-358. https://doi.org/10.1016/j.egypro.2018.10.038.

[31] BANDYOPADHYAY P, BHATTACHARYA S K, KASHYAP S K. Assessment of noise environment in a major railway station in India. Industrial health, 1994, 32(3): 187-192. https://doi.org/10.2486/indhealth.32.187.

[32] Liu G, Hou D, Wang L, et al. Acoustics testing and simulation analysis of waiting hall in the line-side high-speed railway station. The Journal of the Acoustical Society of America, 2014, 135(4): 2332-2332. https://doi.org/10.1121/1.4877651. 
[33] Tao Z, Wang Y, Zou C, et al. Assessment of ventilation noise impact from metro depot with over-track platform structure on workers and nearby inhabitants. Environmental Science and Pollution Research, 2019, 26(9): 9203-9218. doi: 10.1007/s11356-019-04378-w.

[34] The Paper. The ranking of China's top high-speed railway stations in 2018 based on big data, https://www.135995.com/207/163461.html; 2018 [accessed 04 August 2018].

[35] Li Z H, Zhang X. Simulation and Analysis Based on Emergency Evacuation Success Rate in Elevated Layer of Beijing South Railway Station//Applied Mechanics and Materials. Trans Tech Publications, 2014, 587: 1912-1915.

[36] Shah J, Joshi G J, Parida P. Behavioral characteristics of pedestrian flow on stairway at railway station. Procedia-social and behavioral sciences, 2013, 104: 688-697. https://doi.org/10.1016/j.sbspro.2013.11.163.

[37] Prassler E, Scholz J, Elfes A. Tracking people in a railway station during rush-hour//International Conference on Computer Vision Systems. Springer, Berlin, Heidelberg, 1999: 162-179.

[38] Lin Y H, Chen C F. Passengers' shopping motivations and commercial activities at airports-The moderating effects of time pressure and impulse buying tendency. Tourism Management, 2013, 36: 426-434. https://doi.org/10.1016/j.tourman.2012.09.017.

[39] WANG Y, PENG J. The construction study of place sense of tourism in the areas of high-speed railway station and airport. Tourism Research, 2014, 1.

[40] Yue W, Jian K, Shiwei D. A Study on Evacuation Movement Time in Elevated Railway Waiting Halls. Architectural Journal. 1 (2015) 100-105.

[41] Meng Q, Zhang S, Kang J. Effects of typical dining styles on conversation behaviours and acoustic perception in restaurants in China. Building and Environment, 2017, 121: 148-157. https://doi.org/10.1016/j.buildenv.2017.05.025.

[42] Zahorik P. Assessing auditory distance perception using virtual acoustics. The Journal of the Acoustical Society of America, 2002, 111(4): 1832-1846. https://doi.org/10.1121/1.1458027.

[43] M. Long. Architectural Acoustics, Elsevier Academic Press. 2006.

[44] J. Kang. Urban Sound Environment. Taylor and Francis. London, UK. 2006.

[45] Meng Q, Kang J. The influence of crowd density on the sound environment of commercial pedestrian streets. Science of the Total Environment, 2015, 511: 249-258. https://doi.org/10.1016/j.scitotenv.2014.12.060.

[46] Zwicker E. Procedure for calculating loudness of temporally variable sounds. The Journal of the Acoustical Society of America, 1977, 62(3): 675-682. https://doi.org/10.1121/1.381580.

[47] French N R, Steinberg J C. Factors governing the intelligibility of speech sounds. The journal of the Acoustical society of America, 1947, 19(1): 90-119. https://doi.org/10.1121/1.1916407

[48] Burkard R. Sound pressure level measurement and spectral analysis of brief acoustic transients. Electroencephalography and clinical neurophysiology, 1984, 57(1): 83-91. https://doi.org/10.1016/0013-4694(84)90010-5.

[49] Yu L, Kang J. Factors influencing the sound preference in urban open spaces. Applied Acoustics, 2010, 71(7): 622-633. https://doi.org/10.1016/j.apacoust.2010.02.005.

[50] Liu F, Kang J. Relationship between street scale and subjective assessment of audio-visual environment comfort based on 3D virtual reality and dual-channel acoustic tests. Building and Environment, 2018, 129: 35-45. https://doi.org/10.1016/j.buildenv.2017.11.040.

[51] Sanchez G M E, Van Renterghem T, Sun K, et al. Using Virtual Reality for assessing the role of noise in the audio-visual design of an urban public space. Landscape and Urban Planning, 2017, 167: 98-107. https://doi.org/10.1016/j.landurbplan.2017.05.018.

[52] Yu L, Kang J. Modeling subjective evaluation of soundscape quality in urban open spaces: An artificial neural network approach. The Journal of the Acoustical Society of America, 2009, 126(3): 1163-1174. https://doi.org/10.1121/1.3183377.

[53] George D, Mallery P. IBM SPSS statistics 23 step by step: A simple guide and reference. Routledge, 2016.

[54] Hansen J. Using SPSS for windows and macintosh: analyzing and understanding data. 2005. https://doi.org/10.1198/tas.2005.s139.

[55] Reinten J, Braat-Eggen P E, Hornikx M, et al. The indoor sound environment and human task performance: A literature review on the role of room acoustics. Building and Environment, 2017, 123 : 315-332. https://doi.org/10.1016/j.buildenv.2017.07.005. 
590 [56] John J, Thampuran A L, Premlet B. Objective and subjective evaluation of acoustic comfort in 591 classrooms: A comparative investigation of vernacular and modern school classroom in Kerala. Applied 592 Acoustics, 2016, 104: 33-41. https://doi.org/10.1016/j.apacoust.2015.09.017

593 [57] MacKenzie D J, Galbrun L. Noise levels and noise sources in acute care hospital wards. Building 594 Services Engineering Research and Technology, 2007, 28(2): 117-131. 595 https://doi.org/10.1177/0143624406074468.

596 [58] Yi F, Kang J. Effect of background and foreground music on satisfaction, behavior, and emotional 597 responses in public spaces of shopping malls. Applied Acoustics, 2019, 145: 408-419. 598 https://doi.org/10.1016/j.apacoust.2018.10.029.

599 [59] Kang J. Acoustics in long enclosures with multiple sources. The journal of the Acoustical Society of 600 America 1996;2:985-989.

601 [60] Kang J. A method for predicting acoustic indices in long enclosures. Applied Acoustics 602 1997;51(2):169-180.

603 [61] Kang J. The unsuitability of the classic room acoustical theory in long enclosures. Architectural 604 Science Review 1996;39(2):89-94.

605 [62]Kang J. Sound attenuation in long enclosures. Building and environment 1996;31(3):245-253. 